\title{
Efeito da adubação química na infestação do ácaro rajado e na produção do morangueiro
}

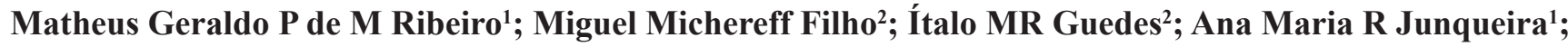 \\ Ronaldo S de $\mathrm{Liz}^{2}$ \\ ${ }^{1}$ UnB-FAV, Agronomia, C. Postal 4.508, 70910-970 Brasília-DF; matheusgpmr@gmail.com; anamaria@unb.br; ${ }^{2}$ Embrapa Hortaliças, C. \\ Postal 218, 70351-970 Brasília-DF; miguel@cnph.embrapa.br; italo@cnph.embrapa.br; setti@cnph.embrapa.br
}

\section{RESUMO}

O objetivo deste trabalho foi determinar o efeito das relações $\mathrm{N}: \mathrm{K}$, aplicadas via fertirrigação, sobre a infestação do ácaro rajado, Tetranychus urticae, e a produtividade de duas cultivares de morangueiro sob cultivo protegido. As plantas receberam, via gotejamento, as seguintes doses referidas em gramas de $\mathrm{N}$ e $\mathrm{K}$ por planta por semana: 0,27 e 0,$13 ; 0,27$ e 0,$50 ; 0,27$ e 0,76 e testemunha (água+micronutrientes). Foram feitas 22 colheitas e avaliadas as características de produção, sendo os frutos classificados em comerciais e refugos. $\mathrm{O}$ estado nutricional das plantas foi avaliado com quatro análises foliares e as densidades populacionais do ácaro foram determinadas semanalmente. Houve interação significativa entre a cultivar Diamante e a maior dose de K, onde as maiores doses propiciaram redução nas densidades populacionais de ovos e formas ativas de $T$. urticae. Os elementos K e P apresentaram correlação negativa para ambas as variáveis, enquanto o $\mathrm{N}$ apresentou correlação positiva. Não houve efeito das adubações sobre as características de produção do morangueiro, provavelmente, por estarem associadas à elevada infestação do ácaro rajado ( $>40$ ácaros/folíolo) em todas as parcelas durante a maior parte do ciclo de cultivo. A simples manipulação das relações entre $\mathrm{N}$ e K no manejo da adubação, nas condições deste experimento, não garantiu o controle do ácaro rajado e nem a redução das perdas ocasionadas pelo mesmo.

Palavras-chave: Tetranychus urticae, Fragaria x ananassa, balanço de nutrientes, estado nutricional da planta, controle da praga.

\begin{abstract}
Effect of chemical fertilization on two-spotted-spider mite infestation and strawberry yield

The effect of $\mathrm{N}: \mathrm{K}$ relationship was evaluated when applied through fertigation, on two-spotted-spider mite, Tetranychus urticae, infestation and on the yield of two strawberry cultivars. Strawberry plants received weekly doses of $\mathrm{N}$ and $\mathrm{K}$ (g/plant) by drip irrigation: 0.27 and $0.13 ; 0.27$ and $0.50 ; 0.27$ and 0.76 and control (water+micronutrients). Fruits were collected twenty two times during crop cycle. Marketable, non-marketable fruits and other yield parameters were evaluated. Leaf nutrient content analysis was performed to determine the nutritional condition of the plants. Population density of T. urticae was evaluated weekly. A significant interaction between $\mathrm{K}$ doses and pest population was observed. Higher doses of the nutrient reduced the number of eggs and active forms of the pest population and the cultivar Diamante showed the smallest pest density. $\mathrm{K}$ and $\mathrm{P}$ showed negative correlation with both variables, but $\mathrm{N}$ showed a positive one. No effects were observed of fertilization on yield parameters due, probably, to the high mite infestation ( $>40$ individuals per leaflet) in all treatments during most of the crop cycle. Solely the use of different $\mathrm{N}: \mathrm{K}$ ratios on the strawberry fertilization management at this specific experimental condition, was not sufficient to control two-spotted spider mite nor to reduce losses caused by that pest.
\end{abstract}

Keywords: Tetranychus urticae, Fragaria $x$ ananassa, nutrient balance, plant nutritional status, pest control.

\section{(Recebido para publicação em 27 de outubro de 2011; aceito em 8 de novembro de 2012) (Received on October 27, 2011; accepted on November 8, 2012)}

$\mathrm{O}$ cultivo do morangueiro (Fragaria $x$ ananassa) já pode ser considerado como tradicional e consolidado na região de Brasília-DF (Henz, 2010). Para essa cultura, o ácaro rajado, Tetranychus urticae (Koch, 1836) (Acari: Tetranychidae) é a principal praga (Lopes et al., 2005). Em decorrência da alimentação de ninfas e adultos nas células do mesófilo foliar, as plantas apresentam queda prematura das folhas e necrose dos tecidos, redução da fotossíntese e transpiração (Sances et al., 1982), podendo resultar na morte da planta ou severa diminuição da produção e qualidade dos frutos (Sato et al., 2002).

De acordo com Meyer (2000), a disponibilidade dos nutrientes no solo não interfere somente nos danos causados pelos insetos às plantas, mas principalmente na capacidade de recuperação das plantas a essas infestações. Chau \& Heong (2005) sugerem que o manejo da adubação pode afetar a suscetibilidade das plantas cultivadas à infestação dos insetos e ácaros, interferindo na sua resistência ou na modificação da sua tolerância à infestação.

O conhecimento das demandas por nutrientes para a cultura do morangueiro e a resposta às adubações são necessários para o entendimento da relação entre a nutrição da planta e a dinâmica populacional do ácaro rajado. Cada relação nutriente-planta-artrópode necessita ser estudada de maneira independente, pois elas apresentam características e relações distintas (Cardoso et al., 2002).

A comparação dos resultados entre plantas com deficiência nutricional, principalmente de $\mathrm{N}$ e $\mathrm{P}$ e plantas com excesso de adubação representa a maioria dos estudos de avaliação da resposta dos ácaros às adubações (Wermelinger 
et al., 1991; Najafabadi et al., 2011). Como o $\mathrm{N}$ e o $\mathrm{P}$, geralmente não são limitantes em solos sob sistema de produção comercial, tais resultados não possuem aplicabilidade direta em programas de manejo integrado de pragas. A avaliação da resposta dos ácaros a plantas não deficientes em nutrientes e o conhecimento das interações da praga com a nutrição hospedeira poderão melhorar as práticas de adubação, reduzir a aplicação excessiva de fertilizantes, favorecer a produção das culturas e reduzir as infestações de ácaros nos cultivos (Chow et al., 2009).

Atualmente, há informações sobre os níveis críticos de nutrientes no solo e no conteúdo foliar de algumas cultivares de morangueiro (Trani \& Raij, 1996), bem como recomendações de adubação para a cultura (Ribeiro et al., 1999; Lopes et al., 2005; Mello et al., 2006). Contudo, pouco se conhece sobre a influência da adubação química na infestação do ácaro rajado em morangueiro nas condições do Cerrado brasileiro. Portanto, este trabalho teve como objetivo determinar a influência das relações molares de $\mathrm{N}$ e K sobre a população do T. urticae em duas cultivares de morangueiro, assim como o efeito dessa interação sobre a produtividade das cultivares.

\section{MATERIAL E MÉTODOS}

O experimento foi conduzido entre abril e dezembro de 2009, na Embrapa Hortaliças, Brasília-DF (1556'S, $48^{\circ} 08^{\prime} \mathrm{O}$, altitude $997 \mathrm{~m}$ ), cujo clima é do tipo Cwa-temperado úmido com inverno seco e verão quente, segundo classificação de Köppen. Os morangueiros foram cultivados em estufa do tipo teto em arco, com $50 \mathrm{~m}$ de comprimento e $8 \mathrm{~m}$ de largura, com pilares de madeira e estrutura metálica, tendo como área útil $336 \mathrm{~m}^{2}$, em dimensões de 7,0 × $48 \mathrm{~m}$.

O solo da estufa foi classificado como Latossolo vermelho distrófico típico, fase Cerrado e textura argilosa. A análise química do solo, em 02/04/2009, 26 dias antes do transplantio das mudas, revelou $\mathrm{pH}$ (água)= 5,6; M.O.= 18,8 g $\mathrm{dm}^{-3} ; \mathrm{H}+\mathrm{Al}=4,5 ; \mathrm{Ca}=6,6 ; \mathrm{Mg}=3,2$ $\left(\mathrm{cmol}_{\mathrm{c}} \mathrm{dm}^{-3}\right) ; \mathrm{P}=98,1 ; \mathrm{K}=175$ e $\mathrm{Na}=$ $5\left(\mathrm{mg} \mathrm{dm}^{-3}\right)$.

A adubação de base foi idêntica para todos os tratamentos, de acordo com a análise de solo e recomendação de Lopes et al. (2005), com a aplicação de 9,37 $\mathrm{g}$ de NPK (fórmula 04-30-16) e 2,31 g de uréia por planta. Os micronutrientes foram aplicados semanalmente via fertirrigação, com $350 \mathrm{~mL}$ por canteiro em 28 semanas, nas seguintes quantidades (g/planta): bórax $=0,065625$; sulfato de zinco $=0,028438$ e sulfato de cobre $=0,032813$.

O plantio de morangueiro foi realizado com as cultivares Oso Grande e Diamante, conduzido diretamente no solo e submetido a três relações molares entre nitrogênio e potássio [3:0,5 $\left(\mathrm{N}_{3} \mathrm{~K}_{0,5}\right) ; 3: 2$ $\left(\mathrm{N}_{3} \mathrm{~K}_{2}\right)$; e $3: 3\left(\mathrm{~N}_{3} \mathrm{~K}_{3}\right)$ ] e uma testemunha (apenas água e micronutrientes). A adubação de cobertura via fertirrigação foi aplicada nas doses ( $\mathrm{kg} / \mathrm{ha}): \mathrm{N}_{3} \mathrm{~K}_{0,5}$ $=324,35$ de $\mathrm{N}$ e 176,92 de $\mathrm{K} ; \mathrm{N}_{3} \mathrm{~K}_{2}=$ 324,35 de $\mathrm{N}$ e 548,77 de $\mathrm{K}$; e $\mathrm{N}_{3} \mathrm{~K}_{3}=$ 324,35 de $\mathrm{N}$ e 807,13 de $\mathrm{K}$.

Como fontes de nitrogênio foram utilizados o nitrato de cálcio $\mathrm{Ca}\left(\mathrm{NO}_{3}\right)^{2}$ e uréia $\left(\mathrm{CH}_{4} \mathrm{~N}_{2} \mathrm{O}\right)$, sendo as fontes de potássio o sulfato e o nitrato de potássio $\left(\mathrm{K}_{2} \mathrm{SO}_{4}\right.$ e $\left.\mathrm{KNO}_{3}\right)$, aplicados via gotejamento e parcelados de acordo com a curva de absorção de nutrientes do morangueiro. As aplicações foram semanais, com a primeira fertirrigação no dia 11 de maio e a última em 23 de novembro.

O delineamento experimental foi em blocos casualizados, no esquema de parcelas subdivididas em faixas "split block” (Banzato \& Kronka, 1992), com quatro repetições. As parcelas principais foram constituídas pelas duas cultivares de morangueiro, sendo completamente casualizadas nos blocos. As subparcelas corresponderam às relações $\mathrm{N}: \mathrm{K}$ e testemunha, as quais foram dispostas em faixas e sem casualização dentro de cada bloco, devido à configuração do sistema de irrigação na estufa.

O transplantio das mudas foi realizado em 28 de abril, em canteiros de $0,7 \mathrm{~m}$ de largura, espaçados de $0,35 \times$ $0,35 \mathrm{~m}$, com duas fileiras por canteiro, utilizando mudas de aproximadamente 8 cm de altura, com três ou quatro folhas. Cada parcela teve área de $2,94 \mathrm{~m}^{2} \mathrm{e}$ foi constituída por 20 plantas. Sobre os canteiros, utilizou-se cobertura plástica (mulch) dupla face, colocando-se a face preta voltada para o solo e a face branca para cima. A irrigação foi realizada por gotejamento, com duas fitas por canteiro, no espaçamento de $0,30 \mathrm{~cm}$ entre as fitas e entre plantas. No período entre 15 maio e 23 novembro, a vazão nominal utilizada foi de $8 \mathrm{~L} / \mathrm{h}$, em turnos de 10 minutos para fertirrigação e 10 minutos para disponibilizar apenas água, em frequência de duas vezes por semana.

Para avaliação do estado nutricional do morangueiro, foram amostradas a $3^{\mathrm{a}}$ e a $4^{\mathrm{a}}$ folhas recém-desenvolvidas e sem pecíolo de 20 plantas por parcela. Foram realizadas quatro avaliações, em 21/08, 26/10, 24/11 e 15/12. As amostras foram acondicionadas em estufa, secas na temperatura de $45^{\circ} \mathrm{C}$ durante 62 horas, e avaliadas em laboratório da Embrapa Hortaliças quanto aos teores de macro e micronutrientes, segundo métodos descritos por Nogueira \& Souza (2005). Os resultados foram comparados com os níveis críticos de nutrientes para morangueiro, propostos por Trani \& Raij (1996).

Foram realizadas 22 colheitas semanais de frutos ao longo do experimento, entre 06/07 e 08/12. Foram avaliados a produção total e comercial por planta, produção não comercial $(\%)$, número total de frutos por planta, número de frutos comerciais por planta e peso médio de frutos comerciais.

O monitoramento populacional do ácaro rajado foi iniciado quando se encontrou pelo menos um ácaro adulto por folíolo em $30 \%$ das plantas, com o total de 15 avaliações semanais, entre 22/05 e 08/12. Para avaliar a infestação, 10 folíolos da porção mediana do dossel do morangueiro foram obtidos aleatoriamente por parcela e coletados, totalizando 320 folíolos por data de amostragem e 4.800 folíolos nas 15 avaliações, com a inspeção via contagem de ovos e de formas ativas (imaturos + adultos) do ácaro. As amostras foram identificadas, acondicionadas em sacos de papel pardo e mantidas em freezer até serem avaliadas. Os ácaros foram contados diretamente nos folíolos com auxílio de microscópio estereoscópico com aumento de 40 vezes e expressos como número de ovos e formas ativas por folíolo.

Os dados de densidade populacional 
do ácaro rajado, produção de frutos comerciais e refugos foram submetidos à análise de variância, enquanto as médias foram comparadas pelo teste de Tukey a $5 \%$ de probabilidade. As análises estatísticas foram realizadas com o auxílio do programa computacional SAS 8.2, por meio dos procedimentos PROC Anova (SAS Institute, 2001). Os teores foliares de macronutrientes (N, P, S, K, Ca e $\mathrm{Mg}$ ) foram relacionados (correlação de Pearson) com as densidades populacionais de ovos e formas ativas do ácaro rajado. Para isso, foram considerados os dados de monitoramento da praga correspondentes a cada data em que foram coletados folíolos para a análise foliar.

\section{RESULTADOS E DISCUSSÃO}

As relações molares $\mathrm{N}: \mathrm{K}$ utilizadas na fertirrigação do morangueiro não afetaram substancialmente o estado nutricional das plantas (Tabela 1). Em todos os tratamentos, os teores foliares de $\mathrm{N}, \mathrm{K}, \mathrm{Ca}$ e $\mathrm{S}$ se enquadraram dentro da faixa considerada adequada para morangueiro, segundo Trani \& Raij (1996). Apenas os teores foliares de P e $\mathrm{Mg}$ estiveram, respectivamente, acima e abaixo das faixas de suficiência $(\mathrm{P}=2-4$ $\mathrm{g} \mathrm{kg}^{-1} ; \mathrm{Mg}=6-10 \mathrm{~g} \mathrm{~kg}^{-1}$ ).

Observaram-se diferenças quanti- tativas de $\mathrm{N}, \mathrm{P}, \mathrm{K}$ e $\mathrm{Mg}$ nas folhas do morangueiro em razão da fertirrigação, da cultivar e da interação destes fatores. Os teores foliares de $\mathrm{N}$ foram similares entre cultivares de morangueiro $\left(\mathrm{F}_{3,9}=\right.$ $17,77 ; \mathrm{P}=0,0004)$ e significativamente menores $\left(\mathrm{F}_{1,3}=0,02 ; \mathrm{P}=0,8893\right)$ na testemunha e na fertirrigação com $\mathrm{N}_{3} \mathrm{~K}_{3}$, as quais diferiram significativamente entre si e dos demais tratamentos.

$\mathrm{O}$ teor foliar de $\mathrm{N}$ nas plantas sem adubação nitrogenada (Tabela 1) ficou dentro do nível adequado, provavelmente porque a mineralização da matéria orgânica do solo supriu boa parte da necessidade de $\mathrm{N}$, sem resultar em deficiência nutricional. Contudo, o menor teor de $\mathrm{N}$ na testemunha refletiu a exaustão progressiva do estoque de $\mathrm{N}$ no solo.

$\mathrm{O}$ incremento do teor de $\mathrm{K}$ na planta pode ocasionar aumento na produção de fotoassimilados e, consequentemente, maior mobilização de $\mathrm{N}$ foliar na síntese de macromoléculas, as quais passam a ser utilizadas no crescimento vegetativo e na produção dos frutos (Dechen \& Nachtigall, 2007). O nitrogênio foliar se desloca das folhas para os frutos durante a frutificação e quase metade das quantidades de $\mathrm{N}$ e $\mathrm{K}$ presentes nas diversas estruturas da planta, é translocada pelos frutos, levando à diminuição das concentrações dos compostos nas folhas a partir do início da frutificação (Demirsoy et al., 2010).

Os teores foliares de $\mathrm{K}$ evidenciaram interação significativa entre a relação molar $\mathrm{N}: \mathrm{K}$ aplicada e cultivar de morangueiro $\left(\mathrm{F}_{3,9}=8,77 ; \mathrm{P}=0,0049\right)$. Verificou-se maior teor de $\mathrm{K}$ nas folhas de plantas fertirrigadas com $\mathrm{N}_{3} \mathrm{~K}_{3}$ em comparação aos outros tratamentos (Tabela 1). Nesta relação molar N:K, o teor foliar de $\mathrm{K}$ foi significativamente maior na cultivar Diamante em relação à Oso Grande. Para as demais relações $\mathrm{N}: \mathrm{K}$, não se observaram diferenças significativas no teor foliar de $\mathrm{K}$ em ambas cultivares, o que revela que não houve resposta linear do morangueiro às doses crescentes de $\mathrm{K}$ aplicadas na fertirrigação. Este efeito (inibição competitiva entre K, Ca e Mg) somente foi superado quando adotado o maior nível de adubação potássica $\left(\mathrm{N}_{3} \mathrm{~K}_{3}=807,1 \mathrm{~kg} / \mathrm{ha}\right.$ de $\mathrm{K})$, provavelmente, em razão da grande absorção de $\mathrm{K}$ pelo processo de fluxo de massa (Dechen \& Nachtigall, 2007).

$\mathrm{O}$ maior teor de $\mathrm{K}$ nas folhas da cultivar Diamante poderia ser explicado por dois fatores não excludentes. No experimento, esta cultivar apresentou desenvolvimento mais lento que a Oso Grande, verificado tanto pelo menor vigor, e tamanho inferior das folhas até o final de maio, como também pela

Tabela 1. Teores foliares de macronutrientes $(\mathrm{g} / \mathrm{kg}$; média $\pm \mathrm{EP})$ em morangueiro das cultivares Oso Grande e Diamante, submetidas à fertirrigação com diferentes relações molares de N e K (leaf macronutrient contents (mean \pm SE) on Oso Grande and Diamante strawberry cultivars, fertigated with different N:K molar relationships). Brasília, Embrapa Hortaliças, 2009.

\begin{tabular}{|c|c|c|c|c|c|c|}
\hline \multirow{2}{*}{ Relações N:K ${ }^{1}$} & \multicolumn{2}{|c|}{$\mathbf{N}(\mathrm{g} / \mathrm{kg})$} & \multicolumn{2}{|c|}{$\mathbf{K}(\mathrm{g} / \mathrm{kg})$} & \multicolumn{2}{|c|}{$\mathbf{P}(\mathrm{g} / \mathrm{kg})$} \\
\hline & Oso & Diamante & Oso & Diamante & Oso & Diamante \\
\hline $\mathrm{N}_{3} \mathrm{~K}_{0,5}$ & $24,2 \pm 0,2 \mathrm{aA}$ & $24,1 \pm 0,4 \mathrm{aA}$ & $28,0 \pm 0,4 \mathrm{bA}$ & $29,8 \pm 0,2 \mathrm{bA}$ & $4,4 \pm 0,1 \mathrm{bA}$ & $4,3 \pm 0,1 \mathrm{bA}$ \\
\hline $\mathrm{N}_{3} \mathrm{~K}_{2}$ & $23,9 \pm 0,2 \mathrm{aA}$ & $23,7 \pm 0,3 \mathrm{aA}$ & $28,5 \pm 0,6 \mathrm{bA}$ & $29,4 \pm 0,8 \mathrm{bA}$ & $4,6 \pm 0,1 \mathrm{aA}$ & $4,8 \pm 0,1 \mathrm{aA}$ \\
\hline $\mathrm{N}_{3} \mathrm{~K}_{3}$ & $23,0 \pm 0,1 \mathrm{bA}$ & $23,0 \pm 0,3 \mathrm{bA}$ & $33,5 \pm 0,2 \mathrm{aB}$ & $38,7 \pm 1,1 \mathrm{aA}$ & $4,5 \pm 0,1 \mathrm{aA}$ & $4,9 \pm 0,2 \mathrm{aA}$ \\
\hline Testemunha & $21,9 \pm 0,2 \mathrm{cA}$ & $22,4 \pm 0,3 \mathrm{cA}$ & $28,0 \pm 0,2 \mathrm{bA}$ & $28,4 \pm 0,3 \mathrm{bA}$ & $4,3 \pm 0,1 \mathrm{bA}$ & $4,3 \pm 0,1 \mathrm{bA}$ \\
\hline CV (\%) & 4,4 & 3,3 & 5,5 & 7,6 & 6,0 & 7,8 \\
\hline \multirow{2}{*}{ Relações N:K ${ }^{1}$} & \multicolumn{2}{|c|}{ Ca $(\mathrm{g} / \mathrm{kg})$} & \multicolumn{2}{|c|}{$\mathbf{M g}(\mathrm{g} / \mathrm{kg})$} & \multicolumn{2}{|c|}{$\mathbf{s}(\mathrm{g} / \mathrm{kg})$} \\
\hline & Oso & Diamante & Oso & Diamante & Oso & Diamante \\
\hline $\mathrm{N}_{3} \mathrm{~K}_{0,5}$ & $16,2 \pm 0,8 \mathrm{aA}$ & $16,1 \pm 0,6 \mathrm{aA}$ & $4,5 \pm 0,2$ aA & $4,3 \pm 0,1 \mathrm{aA}$ & $1,6 \pm 0,2 \mathrm{aA}$ & $1,4 \pm 0,2 \mathrm{aA}$ \\
\hline $\mathrm{N}_{3} \mathrm{~K}_{2}$ & $15,9 \pm 0,4 \mathrm{aA}$ & $15,0 \pm 0,4 \mathrm{aA}$ & $4,0 \pm 0,1 \mathrm{bA}$ & $4,0 \pm 0,1 \mathrm{bA}$ & $1,5 \pm 0,1 \mathrm{aA}$ & $1,5 \pm 0,1 \mathrm{aA}$ \\
\hline $\mathrm{N}_{3} \mathrm{~K}_{3}$ & $15,8 \pm 0,3 \mathrm{aA}$ & $16,8 \pm 1,0 \mathrm{aA}$ & $4,0 \pm 0,1 \mathrm{bA}$ & $4,0 \pm 0,2 \mathrm{bA}$ & $1,5 \pm 0,2 \mathrm{aA}$ & $1,5 \pm 0,1 \mathrm{aA}$ \\
\hline Testemunha & $17,0 \pm 0,7 \mathrm{aA}$ & $15,4 \pm 0,4 \mathrm{aA}$ & $4,3 \pm 0,1 \mathrm{aA}$ & $4,2 \pm 0,1 \mathrm{aA}$ & $1,5 \pm 0,1 \mathrm{aA}$ & $1,4 \pm 0,1 \mathrm{aA}$ \\
\hline $\begin{array}{l}\mathrm{CV}(\%) \\
\end{array}$ & 7,9 & 8,7 & 7,5 & 6,0 & 5,8 & 5,5 \\
\hline
\end{tabular}

Médias seguidas pela mesma letra minúscula, na coluna e maiúsculas na linha, não diferem entre si pelo teste de Tukey a $5 \%$ de probabilidade. $\mathrm{N}=32$ (means followed by same lower case letter in the columns and upper case in rows do not differ by Tukey test, at $5 \%$ probability. $\mathrm{N}=32$ ). 
Tabela 2. Densidades populacionais totais (média \pm EP) de Tetranychus urticae em plantas de morangueiro das cultivares Oso Grande e Diamante, submetidas à fertirrigação com diferentes relações entre $\mathrm{N}$ e K (population densities (mean $\pm \mathrm{SE}$ ) of Tetranychus urticae on Oso Grande and Diamante strawberry cultivars, fertigated with different N and K molar relationships). Brasília, Embrapa Hortaliças, 2009.

\begin{tabular}{|c|c|c|c|c|}
\hline \multirow{3}{*}{ Relações N:K } & \multicolumn{4}{|c|}{ Indivíduos/folíolo } \\
\hline & \multicolumn{2}{|c|}{ Formas ativas } & \multicolumn{2}{|c|}{ Ovos } \\
\hline & Oso Grande & Diamante & Oso Grande & Diamante \\
\hline $\mathrm{N}_{3} \mathrm{~K}_{0,5}$ & $79,4 \pm 7,6 \mathrm{aA}$ & $73,1 \pm 5,3 \mathrm{aA}$ & $69,4 \pm 5,8$ aA & $65,1 \pm 3,1 \mathrm{aA}$ \\
\hline $\mathrm{N}_{3} \mathrm{~K}_{2}$ & $79,5 \pm 5,8 \mathrm{aA}$ & $80,3 \pm 5,4$ aA & $68,7 \pm 5,5 \mathrm{aA}$ & $66,9 \pm 4,1 \mathrm{aA}$ \\
\hline $\mathrm{N}_{3} \mathrm{~K}_{3}$ & $66,1 \pm 3,8 \mathrm{bA}$ & $55,2 \pm 1,3 \mathrm{bB}$ & $56,1 \pm 1,0 \mathrm{bA}$ & $50,0 \pm 0,2 \mathrm{bB}$ \\
\hline Testemunha & $80,8 \pm 3,2 \mathrm{aA}$ & $75,9 \pm 2,3 \mathrm{aA}$ & $64,8 \pm 1,9 \mathrm{aA}$ & $60,2 \pm 1,2 \mathrm{aA}$ \\
\hline $\mathrm{CV}(\%)$ & 33,1 & 28,3 & 41 & 38,6 \\
\hline
\end{tabular}

Médias seguidas pela mesma letra minúscula, na coluna e maiúsculas na linha, não diferem entre si pelo teste de Tukey, a 5\% de probabilidade. $\mathrm{N}=1.200$ amostras/tratamento (means followed by same lower case letter in the columns and upper case letter in rows do not differ by Tukey test, at $5 \%$ probability. $\mathrm{N}=1,200$ samples per treatment).

abertura das primeiras flores somente em junho. Por outro lado, a cultivar Oso Grande mostrou-se muito vigorosa e teve seu início do florescimento em maio. Assim, a menor expansão da área foliar e lento crescimento das estruturas vegetativas possivelmente contribuíram para menor diluição do $\mathrm{K}$ nas folhas da cultivar Diamante, durante considerável período de tempo no estudo. Aliado a isso, o maior acúmulo de $\mathrm{K}$ nas folhas pode ser uma característica inerente à cultivar, pois há predisposição genética da cultivar Diamante para produção de frutos grandes (Sanhueza, 2005), que por esta razão, pode demandar maior absorção de potássio (Mello et al., 2006; Lester et al., 2010).

Os teores foliares de P não diferiram significativamente entre cultivares $\left(\mathrm{F}_{1,3}=\right.$
$1,09 ; \mathrm{P}=0,3730)$ e foram significativamente maiores $\left(\mathrm{F}_{3,9}=6,45 ; \mathrm{P}=0,0128\right)$ nas fertirrigações com $\mathrm{N}_{3} \mathrm{~K}_{2}$ e $\mathrm{N}_{3} \mathrm{~K}_{3}$ (Tabela 1). Situação oposta ocorreu para os teores foliares de $\mathrm{Mg}$, pois nas fertirrigações com $\mathrm{N}_{3} \mathrm{~K}_{2}$ e $\mathrm{N}_{3} \mathrm{~K}_{3}$ foram observados os menores teores foliares deste nutriente $\left(\mathrm{F}_{3,9}=8,41 ; \mathrm{P}=0,0056\right)$, sem distinção entre cultivares $\left(\mathrm{F}_{1,3}=\right.$ $0,01 ; \mathrm{P}=0,9498)$. Isso, provavelmente,

Tabela 3. Produção total e comercial por planta, produção não comercial (\%), número total de frutos por planta, número de frutos comerciais por planta, peso médio de frutos totais e peso médio de frutos comerciais (média \pm EP), nas cultivares Oso Grande e Diamante, submetidas à fertirrigação com diferentes relações molares de $\mathrm{N}$ e K (total and marketable plant production, non marketable production (\%), total number of fruits per plant, number of marketable fruits per plant, mean weight of total fruits and mean weight of marketable fruits (mean \pm SE), on Oso Grande and Diamante strawberry cultivars, fertigated with different N:K molar relationships). Brasília-DF, 2009.

\begin{tabular}{|c|c|c|c|c|c|c|}
\hline \multirow{2}{*}{ Relações N:K } & \multicolumn{2}{|c|}{ PTO $^{1}$ (g/planta) } & \multicolumn{2}{|c|}{ PCO (g/planta) } & \multicolumn{2}{|c|}{ PNC (\%) } \\
\hline & Oso $^{3}$ & $\mathrm{Dt}^{4}$ & Oso & Dt & Oso & Diamante \\
\hline $\mathrm{N}_{3} \mathrm{~K}_{0,5}$ & $251,2 \pm 27,3 \mathrm{aA}$ & $277,3 \pm 53,1 \mathrm{aA}$ & $244,6 \pm 26,4 \mathrm{aA}$ & $271,8 \pm 50,1 \mathrm{aA}$ & $2,7 \pm 0,7 \mathrm{aA}$ & $1,6 \pm 0,6 \mathrm{aA}$ \\
\hline $\mathrm{N}_{3} \mathrm{~K}_{2}$ & $269,2 \pm 28,2 \mathrm{aA}$ & $255,8 \pm 28,8 \mathrm{aA}$ & $262,0 \pm 26,7 \mathrm{aA}$ & $249,5 \pm 30,1 \mathrm{aA}$ & $2,4 \pm 0,5 \mathrm{aA}$ & $3,4 \pm 1,4 \mathrm{aA}$ \\
\hline $\mathrm{N}_{3} \mathrm{~K}_{3}$ & $276,5 \pm 7,5 \mathrm{aA}$ & $309,0 \pm 36,6$ aA & $272,0 \pm 8,3 \mathrm{aA}$ & $303,5 \pm 35,2 \mathrm{aA}$ & $1,6 \pm 0,4 \mathrm{aA}$ & $2,1 \pm 0,3 \mathrm{aA}$ \\
\hline Testemunha & $275,1 \pm 22,7 \mathrm{aA}$ & $317,4 \pm 44,1 \mathrm{aA}$ & $260,6 \pm 22,4$ aA & $303,6 \pm 39,5 \mathrm{aA}$ & $5,3 \pm 1,1$ aA & $3,9 \pm 1,1 \mathrm{aA}$ \\
\hline CV (\%) & 32,41 & 37,28 & 31,49 & 37,64 & 59,42 & 64,82 \\
\hline \multirow{2}{*}{ Relações N:K } & \multicolumn{2}{|c|}{ NFTP (frutos/planta) } & \multicolumn{2}{|c|}{ NFCP (frutos/planta) } & \multicolumn{2}{|c|}{ PMFC (g/fruto) } \\
\hline & Oso & Dt & Oso & Dt & Oso & Diamante \\
\hline $\mathrm{N}_{3} \mathrm{~K}_{0,5}$ & $20,2 \pm 1,6 \mathrm{aA}$ & $22,4 \pm 4,5 \mathrm{aA}$ & $18,2 \pm 1,7 \mathrm{aA}$ & $20,6 \pm 3,6 \mathrm{aA}$ & $13,4 \pm 0,4 \mathrm{aA}$ & $13,2 \pm 0,4 \mathrm{aA}$ \\
\hline $\mathrm{N}_{3} \mathrm{~K}_{2}$ & $23,2 \pm 2,9 \mathrm{aA}$ & $22,0 \pm 1,9 \mathrm{aA}$ & $20,9 \pm 2,5 \mathrm{aA}$ & $19,5 \pm 2,1$ a A & $12,6 \pm 0,3 \mathrm{aA}$ & $12,7 \pm 0,2 \mathrm{aA}$ \\
\hline $\mathrm{N}_{3} \mathrm{~K}_{3}$ & $23,5 \pm 0,6 \mathrm{aA}$ & $24,9 \pm 2,7 \mathrm{aA}$ & $21,9 \pm 0,6 \mathrm{aA}$ & $22,5 \pm 2,2 \mathrm{aA}$ & $12,5 \pm 0,3 \mathrm{aA}$ & $13,5 \pm 0,5 \mathrm{aA}$ \\
\hline Testemunha & $26,5 \pm 1,3$ aA & $28,4 \pm 5,0 \mathrm{aA}$ & $22,4 \pm 1,3$ aA & $24,4 \pm 3,6 \mathrm{aA}$ & $11,6 \pm 0,5 \mathrm{aA}$ & $12,5 \pm 0,4 \mathrm{aA}$ \\
\hline CV (\%) & 28,62 & 36,4 & 27,02 & 35,9 & 8,83 & 6,04 \\
\hline
\end{tabular}

${ }^{1}$ Componentes de produção: $\mathrm{PTO}=$ produção total por planta; $\mathrm{PCO}=$ produção de frutos comerciais por planta; $\mathrm{PN}=$ porcentagem de produção não comercial (refugos), obtida pela diferença entre produção bruta e produção comercial; NFTP= número total de frutos por planta; NFCP= número de frutos comerciais por planta e $\mathrm{PMFC}=$ peso médio de frutos comerciais. ${ }^{2}$ Não houve efeito significativo (ns) de cultivares, de relações molares de $\mathrm{N}: \mathrm{K}$ e da interação desses fatores nos componentes de produção do morangueiro (Anova, $\mathrm{p}>0,05)$. $\mathrm{N}=22$ colheitas ( 1 production components: $\mathrm{PTO}=$ total plant production; $\mathrm{PCO}=$ marketable plant production; $\mathrm{PNC}=$ percentage of non marketable production, obtained by the difference between gross production and marketable production ( $\mathrm{g} / \mathrm{plant})$; $\mathrm{NFTP}=$ total number of fruits per plant; $\mathrm{NFCP}=$ number of marketable fruits per plant and $\mathrm{PMFC}=$ mean weight of marketable fruits. ${ }^{2}$ There was no significant effect (ns) of cultivars, $\mathrm{N}: \mathrm{K}$ molar relationships and their interaction on strawberry production components (Anova, $\mathrm{p}>0.05$ ). $\mathrm{N}=22$ harvests). 


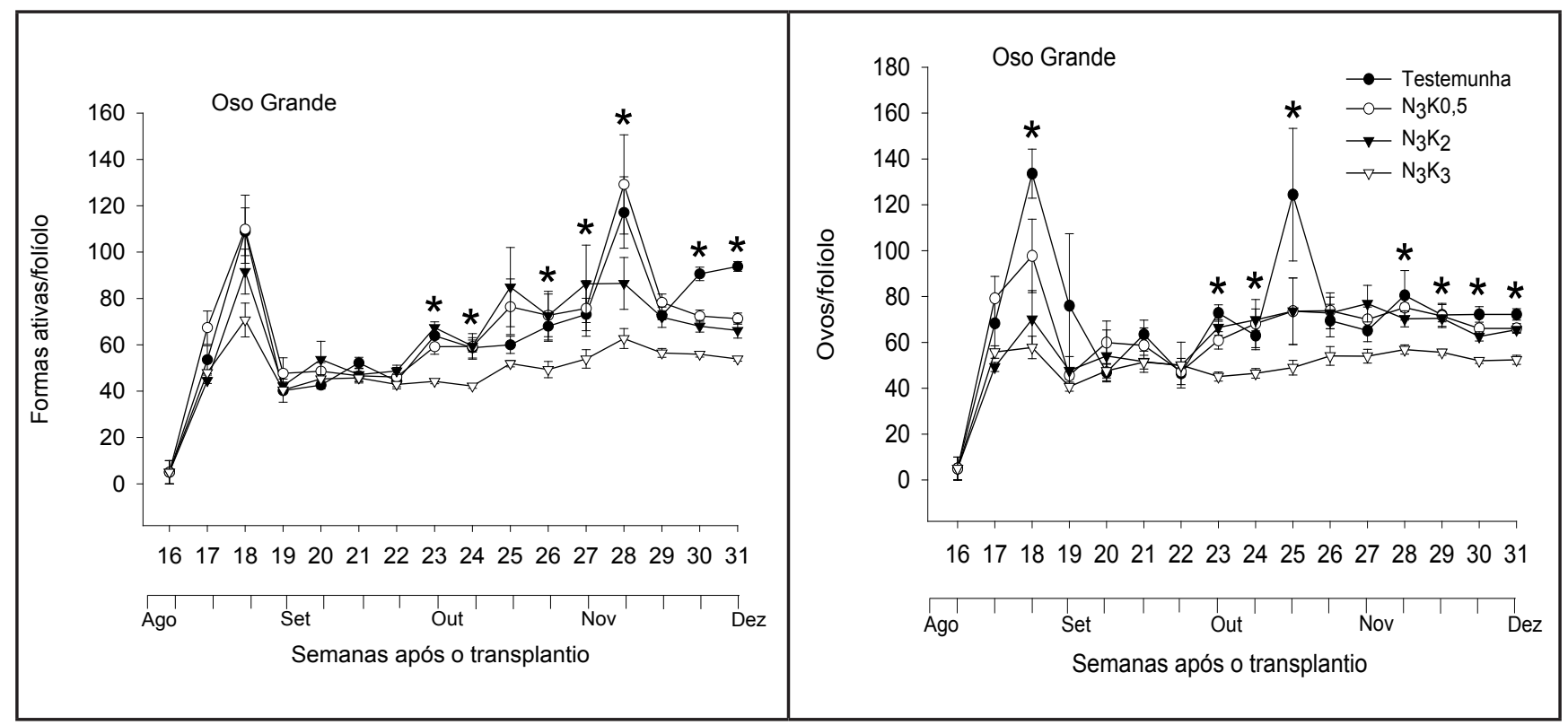

Figura 1. Flutuação populacional de Tetranychus urticae em plantas de morangueiro, cultivar Oso Grande, submetidas à fertirrigação com diferentes relações de N e K. Transplantio em 28/04/09. Início da fertigação na segunda semana após o transplantio. Avaliações realizadas entre agosto e dezembro de 2009; médias ( \pm EP) seguidas por um asterisco são significativamente diferentes para aquela época de amostragem, pelo teste de Tukey a $5 \%$ de probabilidade. $\mathrm{N}=40$ folíolos/tratamento (population fluctuation of Tetranychus urticae on strawberry plants, cultivar Oso Grande, fertigated with different N and K relationship. Transplanting started at April 28 ${ }^{\text {th }}$, 2009, and the fertigation, at the second week after transplanting. The evaluations were carried out between August and December, 2009. Means ( \pm SE) followed by an asterisk are significantly different at that particular sampling date by Tukey test, at $5 \%$ probability. $\mathrm{N}=40$ leaflets per treatment). Brasília, Embrapa Hortaliças, 2009.

pode estar associado à inibição competitiva na absorção de $\mathrm{Mg}$ exercida pelo teor de $\mathrm{K}$ no solo, sendo mais crítico nas parcelas que receberam os maiores níveis de adubação potássica (380-650 $\mathrm{mg} / \mathrm{dm}^{3}$ de K).

Os teores foliares de $\mathrm{Ca}$ e $\mathrm{S}$ foram similares em ambas cultivares de morangueiro e não se detectaram efeitos significativos da fertirrigação (Tabela 1).

O início da infestação de $T$. urticae nos morangueiros foi detectado em $14 / 08$, correspondendo à $16^{\mathrm{a}}$ semana do transplantio e $11^{\text {a }}$ semana do início das fertirrigações, com 2-8 formas ativas/ folíolos e 5-14 ovos/folíolo, respectivamente, sem diferença significativa entre tratamentos (Figuras 1 e 2). O primeiro pico populacional em ambas cultivares ocorreu após a $18^{\mathrm{a}}$ semana do transplantio, com 52-125 formas ativas/ folíolo e 57-144 ovos/folíolo, respectivamente. $\mathrm{Na} 19^{\mathrm{a}}$ semana do transplantio (início de setembro), houve declínio nas populações do ácaro rajado em todos os tratamentos, mantendo-se oscilantes entre 35-54 formas ativas/folíolo e 38-67 ovos/folíolo, respectivamente até a $22^{\mathrm{a}}$ semana (final de setembro).
As diferenças na dinâmica populacional desta praga entre os tratamentos foram detectadas depois da $23^{\text {a }}$ semana do transplantio ou da $18^{\mathrm{a}}$ semana do início das fertirrigações e início de outubro em diante (Figuras 1 e 2). Em várias ocasiões desse período, as populações de T. urticae foram distintamente mais baixas e menos oscilantes nas parcelas fertirrigadas com $\mathrm{N}_{3} \mathrm{~K}_{3}$ em relação àquelas da testemunha e demais relações $\mathrm{N}: \mathrm{K}$ testadas. Para as formas ativas do ácaro rajado, este padrão de resposta ficou mais evidente a partir da $28^{\mathrm{a}}$ semana ou na primeira quinzena de novembro, quando se notou outro grande pico populacional, tanto na cultivar Oso Grande como na Diamante (55-151 indivíduos/ folíolo). Para o número de ovos por folíolo, tais diferenças entre tratamentos foram previamente constatadas na $23^{\mathrm{a}}$ semana e se mantiveram na maioria das avaliações até o final do estudo, em ambas cultivares de morangueiro.

Com base no nível de controle proposto por Sato et al. (2002), que é de 10 ácaros por folíolo, verificou-se que a infestação inicial do ácaro rajado foi tardia (Figuras 1 e 2), porém sempre muito alta, e os maiores picos populacionais coincidiram com o período mais seco do ano (agosto-setembro), corroborando com Lopes et al. (2005) que afirmam que as maiores densidades populacionais de T. urticae nos cultivos de morangueiro da região Centro-Oeste são observadas entre agosto e outubro. No presente estudo a infestação do ácaro rajado foi severo, mantendo-se acima de 40 formas ativas/folíolo ao longo do ciclo do morangueiro, inclusive nas parcelas fertirrigadas com $\mathrm{N}_{3} \mathrm{~K}_{3}$.

No conjunto das avaliações da infestação de T. urticae ao morangueiro (Tabela 2), constatou-se interação significativa entre a relação molar N:K utilizada na fertirrigação e a cultivar de morangueiro, tanto para formas ativas $\left(\mathrm{F}_{3,9}=6,83 ; \mathrm{P}=0,0042\right)$, como para ovos da praga $\left(\mathrm{F}_{3,9}=10,09 ; \mathrm{P}=0,0031\right)$. As densidades populacionais do ácaro rajado foram significativamente menores nas plantas fertirrigadas com $\mathrm{N}_{3} \mathrm{~K}_{3} \mathrm{em}$ relação aos demais tratamentos. Nesta mesma relação molar $\mathrm{N}: \mathrm{K}$, a cultivar Diamante foi menos infestada e apresentou maior teor foliar de $\mathrm{K}$ que a Oso Grande (Tabelas 1 e 2). 


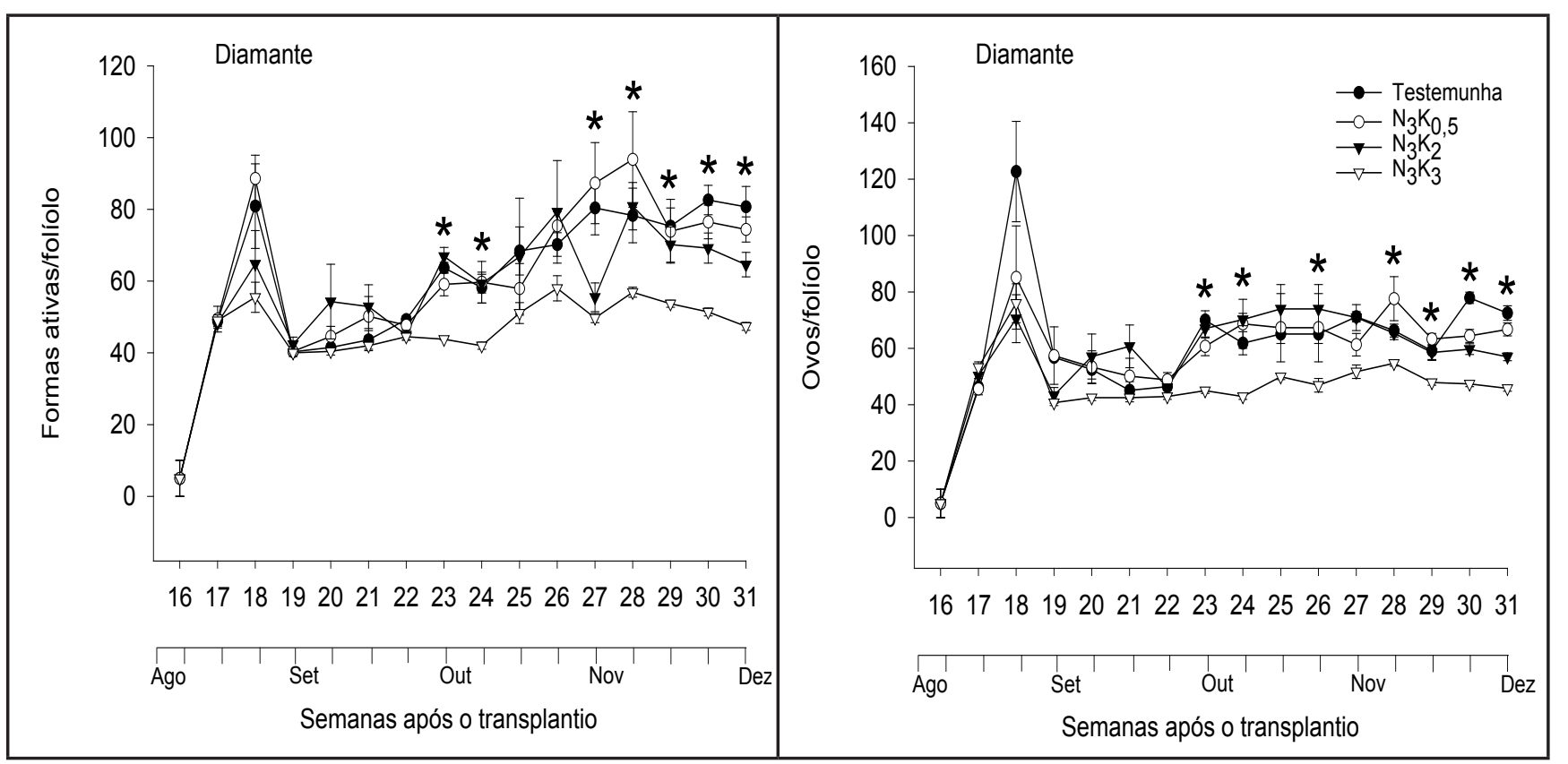

Figura 2. Flutuação populacional de Tetranychus urticae em plantas de morangueiro, cultivar Diamante, submetidas à fertirrigação com diferentes relações de N e K. Transplantio em 28/04/09. Início da fertigação na segunda semana após o transplantio. Avaliações realizadas entre agosto e dezembro de 2009. Médias ( \pm EP) seguidas por um asterisco são significativamente diferentes para aquela época de amostragem, pelo teste de Tukey a 5\% de probabilidade. $\mathrm{N}=40$ folíolos/tratamento (population fluctuation of Tetranychus urticae on strawberry plants, cultivar Diamante, fertigated with different N and K relationship. Transplanting started at April 28 ${ }^{\text {th }}, 2009$, and the fertigation, at the second week after transplanting. The evaluations were carried out between August and December, 2009. Means ( \pm SE) followed by an asterisk are significantly different at that particular sampling date by Tukey test, at $5 \%$ probability. $\mathrm{N}=40$ leaflets per treatment). Brasília, Embrapa Hortaliças, 2009.

A infestação do ácaro rajado foi relacionada com os teores de $\mathrm{N}, \mathrm{K}$ e $\mathrm{P}$ nas folhas do morangueiro. Correlações negativas entre os teores foliares de $\mathrm{K}$ e $\mathrm{P}$ e as densidades de formas ativas por folíolo (K: $r=-0,64 ; \mathrm{P}<0,01 ; \mathrm{P}: \mathrm{r}=-0,76$; $\mathrm{P}<0,01)$ e ovos $(\mathrm{K}: \mathrm{r}=-0,65 ; \mathrm{P}<0,01 ; \mathrm{P}$ : $r=-0,58 ; P<0,01)$ indicam que o aumento na concentração destes nutrientes na planta afetou negativamente os diferentes estádios de desenvolvimento da praga. Por outro lado, o teor foliar de $\mathrm{N}$ teve efeito positivo sobre T. urticae, porém, em menor magnitude que $\mathrm{K}$ e $\mathrm{P}$, tendo em vista a fraca correlação com a densidade populacional de formas ativas $(\mathrm{r}=0,18 ; \mathrm{P}<0,05)$ e ovos $(\mathrm{r}=0,25$; $\mathrm{P}<0,01)$. Estes resultados mostraram que a população do ácaro rajado foi influenciada pela relação molar $\mathrm{N}: \mathrm{K}$ utilizada na adubação e pelos teores de nutrientes nas folhas do morangueiro. A densidade populacional e a reprodução, principalmente fecundidade, do ácaro rajado também foram correlacionadas positivamente com altos teores foliares de $\mathrm{N}$ em outros estudos de nutrição envolvendo morangueiro (Daugherty,
2011), roseira (Chow et al., 2009), feijoeiro (Suski \& Badowska, 1975; Najafabadi et al 2011), soja (Busch \& Phelan, 1999), algodoeiro (Wilson, 1994) e macieira (Wermelinger et al., 1991).

Correlações negativas entre os teores foliares de $\mathrm{K}$ e a taxa de crescimento populacional de T. urticae foram observadas em feijoeiro (Suski \& Badowska, 1975; Mohiseni et al., 2011), assim como altas taxas de mortalidade nas fases imaturas de $T$. urticae em abacateiro ocorreram com o incremento da adubação potássica (Jesiotr et al., 1979).

Os teores foliares de $\mathrm{P}$ nos quais a oviposição de T. urticae aumenta ou reduz variam entre espécies de plantas hospedeiras e dependem do estado nutricional (Chen et al., 2007; Chow et al., 2009). Em vários casos, as respostas positivas entre o suprimento de $\mathrm{P}$ e o crescimento populacional de $T$. urticae foram observadas em plantas originalmente com deficiência ou na zona de consumo de luxo para este nutriente (Suski \& Badowska,1975; Wermelinger et al., 1991; Opit et al.,
2005). No entanto, no presente estudo os teores foliares de $\mathrm{P}$ se enquadraram dentro da faixa de suficiência para o morangueiro, e o nível deste nutriente esteve associado negativamente com a infestação do ácaro-praga.

A proporção entre nutrientes minerais na planta é outro importante aspecto que deve ser considerado para compreensão dos efeitos da nutrição vegetal na interação planta-herbívoro (Mellors \& Propts, 1983; Busch \& Phelan, 1999; Mohiseni et al., 2011). Enquanto a concentração de um nutriente pode ter impacto sobre a herbivoria, o efeito pode depender também da quantidade em relação aos outros minerais. Grandes populações de $T$. urticae em plantas de rabanete foram associadas a altas proporções de N sobre P e K (Mellors \& Propts, 1983), enquanto esta mesma espécie apresentou baixas taxas de crescimento populacional quando plantas de soja foram supridas com proporções muito baixas e muito altas de $\mathrm{P}$ em relação ao $\mathrm{N}$ e S (Busch \& Phelan, 1999). Mohiseni et al. (2011), verificaram que a densida- 
de populacional de T. urticae por folha de feijoeiro foram significativamente menores nas plantas que receberam altas proporções de $\mathrm{P}$ e K sobre N, e maiores densidades populacionais ocorreram nos tratamentos com altas proporções de $\mathrm{N}$ sobre P e K.

Neste estudo também se evidenciou a importância da relação molar $\mathrm{N}: \mathrm{K}$ na adubação do morangueiro sobre a intensidade de infestação do ácaro rajado. As duas cultivares de morangueiro quando adubadas com maior proporção de $\mathrm{K}$ sobre $\mathrm{N}\left(\mathrm{N}_{3} \mathrm{~K}_{3} ; 324,3 \mathrm{~kg} /\right.$ ha de $\mathrm{N}$ x $807,0 \mathrm{~kg} /$ ha de K) também apresentaram níveis superiores de potássio em relação ao nitrogênio nas folhas e as plantas manifestaram as menores densidades populacionais do ácaro rajado.

As diferenças significativas na infestação do ácaro rajado e nos teores foliares de nutrientes entre tratamentos não tiveram reflexo nos componentes de produção do morangueiro (Tabela 3). Não houve efeito significativo das relações molares $\mathrm{N}: \mathrm{K}$, de cultivares e da interação destes fatores na produção total e comercial por planta, na porcentagem de produção não comercial, no número total de frutos por planta, no número de frutos comerciais por planta e no peso médio de frutos comerciais. A produção total de frutos por planta variou entre 251,1 e $317,4 \mathrm{~g} /$ planta, enquanto a produção comercial ficou entre 244,6 e 303,6 g/planta, resultando em $1,6 \%$ a 3,9\% de produção não comercial (refugos). Para o número de frutos produzidos, obteve-se o total de 20,2 a 28,4 frutos/planta, e de 18,2 a 24,4 frutos comerciais/planta, respectivamente. $\mathrm{O}$ peso médio de frutos comerciais oscilou entre 11,6 e 13,5 g/fruto.

Praticamente não existem informações sobre os componentes de produção das cultivares Oso Grande e Diamante sob condições de manejo, solo e clima semelhantes ao presente estudo, o que torna limitada a comparação dos valores aqui gerados com outros trabalhos. A análise da produção média de frutos comerciais por planta das cultivares Oso Grande (260,6 g/planta) e Diamante (303,3 g/planta) e da densidade de 46.667 plantas/ha e da produtividade de 12,2 e 14,2 t/ha, respectivamente, indica que estes níveis de produtivida- de não foram satisfatórios, visto que a produtividade média da cultura do morangueiro no Distrito Federal está entre 24 e 45 t/ha, com densidades variando entre 50.000 a 72.000 plantas/ha (Lopes et al., 2005; Henz, 2010).

Os níveis de $\mathrm{N}$ e $\mathrm{K}$ utilizados para compor o tratamento $\mathrm{N}_{3} \mathrm{~K}_{0,5}(324,3 \mathrm{~kg} / \mathrm{ha}$ de $\mathrm{N}$ e $176,9 \mathrm{~kg} /$ ha de K) estão dentro da faixa de adubação (220-402 kg/ha de N e $66-406 \mathrm{~kg} / \mathrm{ha}$ de $\mathrm{K}$, respectivamente) recomendada para a produção de morangueiro em São Paulo, Minas Gerais e Distrito Federal (Passos et al., 1998; Ribeiro et al., 1999; Lopes et al., 2005; Mello et al., 2006). Os níveis de potássio nos tratamentos $\mathrm{N}_{3} \mathrm{~K}_{2}(548,8 \mathrm{~kg} / \mathrm{ha}$ de K) e $\mathrm{N}_{3} \mathrm{~K}_{3}(807,1 \mathrm{~kg} /$ ha de $\mathrm{K})$ corresponderam aos incrementos de $73,1 \% \mathrm{e}$ $154,5 \%$, respectivamente, em relação à faixa mediana de adubação adotada naqueles estados. Portanto, a falta de resposta em produtividade do morangueiro aos tratamentos de fertirrigação não era esperada e, provavelmente, esteve associada à elevada infestação do ácaro rajado (>40 ácaros/folíolo) em todas as parcelas durante a maior parte do ciclo de cultivo.

As densidades populacionais de ovos e formas ativas do ácaro T. urticae em morangueiro são influenciadas pelos níveis de $\mathrm{N}$ e $\mathrm{K}$ aplicados via fertirrigação, sendo com maior efeito redutor na proporção de $0,27 \mathrm{~g}$ de $\mathrm{N}$ e $0,76 \mathrm{~g}$ de $\mathrm{K}$ por planta por semana. As cultivares de morangueiro apresentam variabilidade de resposta à absorção de $\mathrm{K}$ e à infestação de T. urticae, sendo que a cultivar Diamante é mais exigente e apresenta as menores quantidades de ovos e formas ativas por folíolo que a cultivar Oso Grande e o P, quando disponibilizado na dose de $0,02 \mathrm{~g} /$ planta por semana reduz as densidades populacionais do T. urticae em morangueiro.

Conclui-se que, mesmo com nutrição adequada, o morangueiro é suscetível à infestação e a perdas severas pelo ácaro rajado. A adubação nitrogenada deve ser realizada de maneira mais cautelosa, visto sua influência no aumento da densidade populacional de T. urticae e embora o aumento na proporção de $\mathrm{K}$ na adubação química do morangueiro possa afetar negativamente a dinâmica populacional do ácaro rajado, tal prática aplicada isoladamente não garante o controle desta praga e o alcance da produtividade esperada. Portanto, a adoção do manejo da adubação juntamente com outras táticas de controle (acaricidas seletivos e liberação de ácaros predadores) permanece como uma opção a ser explorada no manejo integrado do ácaro rajado no morangueiro.

\section{AGRADECIMENTOS}

À CAPES/REUNI, pela concessão da bolsa de mestrado e à Embrapa Hortaliças pela logística, supervisão e infra-estrutura disponibilizadas no desenvolvimento do trabalho.

\section{REFERÊNCIAS}

BANZATO DA; KRONKA SN. 1992. Experimentação agrícola. 2.ed. Jaboticabal: FUNEP. 247p.

BUSCH JW; PHELAN PL. 1999. Mixture models of soybean growth and herbivore performance in response to nitrogen-sulfur-phosphorous nutrient interactions. Ecological Entomology 24: $132-145$.

CARDOSO AM; CIVIDANES FJ; NATALE W. 2002. Influência da adubação fosfatadapotássica na ocorrência de pragas na cultura da soja. Anais da Sociedade Entomológica do Brasil 31: 441-444.

CHAU LM; HEONG KL. 2005. Effects of organic fertilizers on insect pest and diseases of rice Omonrice 13: 26-33.

CHEN YGP; OPIT VM; JONAS KA; WILLIAMS JR; NECHOLS; MARGOLIES DC. 2007. Two spotted spider mite population level, distribution, and damage on ivy geranium in response to different nitrogen and phosphorus fertilization regimes. Journal of Economic Entomology 100: 1821-1830.

CHOW AA; CHAU; HEINZ KM. 2009. Reducing fertilization for cut roses: effect on crop productivity and two spotted spider mite abundance, distribution, and management. Journal of Economic Entomology 102: 18961907.

DAUGHERTY MP. 2011. Host plant quality, spatial heterogeneity, and the stability of mite predator-prey dynamics. Experimental and Applied Acarology 53:311-322

DECHEN AR; NACHTIGALL GR. 2007. Elementos requeridos à nutrição de plantas, $\mathrm{p}$. 92-132. In: Novais RF; Alvarez VVH; Barros NF; Fontes RLF; Cantarutti RB; Neves JCL (eds). Fertilidade do Solo. Viçosa: SBCS/ UFV. p. 133.

DEMIRSOY L; DEMIRSOY H; ERSOY B; BALCI G; KIZILKAYA R. 2010. Seasonal variation of $\mathrm{N}, \mathrm{P}, \mathrm{K}$ and $\mathrm{Ca}$ content of leaf, crown and root of "Sweet Charlie" strawberry under different irradiation. Zemdirbyste Agriculture 97: 23-32. 
HENZ GP. 2010. Desafios enfrentados por agricultores familiares na produção de morango no Distrito Federal. Horticultura Brasileira 28: 260-265.

JESIOTR LJ; SUSKI ZW; BADOWSKACZUBIK T. 1979. Food quality influences on a spider mite population, p.189-169. In: Rodriguez JG. (ed). Recent Advances in Acarology, New York: Academic Press. p. 189.

LESTER GE; JIFON JL; MAKUS DJ. 2010. Impact of potassium nutrition on food quality of fruits and vegetables: A condensed and concise review of the literature. Better Crops 94: 18-21.

LOPES HRD; SILVA BC; NASCIMENTO EF; RAMOS LX; PEREIRA M; CARNEIRO RG 2005. A cultura do morangueiro no Distrito Federal. Brasília-DF: EMATER. 76p.

MELLO MS; CARVALHO AM; GUIMARÃES JC. 2006. Nutrição, irrigação e fertirrigação do morangueiro. Boletim do morango: cultivo convencional, segurança alimentar, cultivo orgânico. Belo Horizonte: FAEMG. p. 29-54.

MELLORS WK; PROPTS SE. 1983. Effects of fertilizer level, fertility balance, and soil moisture on the interaction of two spotted spider mites (Acarina: Tetranychidae) with radish plants. Environmental Entomology 2: 1239-1244.

MEYER GA. 2000. Interactive effects of soil fertility and herbivory on Brassica nigra. Oikos 22: 433-441.

MOHISENI A; DASHADI M; SHAHVERDI M; KOOHKI MH. 2011. Effect of macroelements (NPK) in the control of Tetranychus urticae Koch (Acari: Prostigmata: Tetranychidae) on
Derakhshan bean cultivar and its agronomic characteristics. Journal of Plant Protection 25: 107-115.

NAJAFABADI SSM; SHOUSHTARI RV; ZAMANI A; ARBAD M; FARAZMAND H. 2011. Effect of nitrogen fertilization on Tetranychus urticae Koch (Acari: Tetranychidae) populations on common bean cultivars. American-Eurasian Journal of Agriculture \& Environmental Sciences 11: 568-576.

NOGUEIRA ARA; SOUZA GB. 2005. Manual de laboratório: solo, água, nutrição vegetal, nutrição animal e alimentos. São Carlos: Embrapa Pecuária Sudeste. 13p.

OPIT GP; CHEN Y; WILLIAMS KA; NECHOLS JR; MARGOLIES C. 2005. Plant age, fertilization, and biological control affect damage caused by twospotted spider mite on ivy geranium: development of an action threshold. Journal of American Society of Horticultural Science 130: 159-166.

PASSOS FA; TRANI PE; BETTI JA; TANAKA MAS. 1998. Morango. In: FAHL JI; CAMARGO MBP; PIZZINATTO MA; BETTI JA; MELO AMT; MARIA IC; FURLANI AMC. (eds). Instruções agrícolas para as principais culturas econômicas. Campinas-SP: IAC. p. 222-225.

RIBEIRO AC; GUIMARÃES PTG; ALVAREZ VVH. 1999. Recomendações para o uso de corretivos e fertilizantes em Minas Gerais. Viçosa-MG: Comissão de Fertilidade do Solo do Estado de Minas Gerais. 359p.

SANCES FV; TOSCANO NC; OATMAN ER; LAPRE LF; JOHNSON MW; VOTH V. 1982. Reductions in plant processes by Tetranychus urticae (Acarina: Tetranychidae) feeding on strawberry. Environmental Entomology 11: 733-737.

SANHUEZA RMV. 2005. Sistema de produção de morango para mesa na região da Serra Gaúcha e Encosta Superior do Nordeste. Disponível em http://www.embrapa.gov.br. Acessado em: 20 jul. 2009.

SAS INSTITUTE. 2001. SAS user's guide: statistics, version $8.2,6^{\text {th }}$ Editon. SAS Institute, Cary, NC, 943p.

SATO ME; SILVA M; SOUZA-FILHO MF; RAGA A. 2002. Manejo de Tetranychus urticae Koch (Acari: Tetranychidae) em morangueiro utilizando ácaros predadores (Phytoseiidae) e Propargite. Arquivos do Instituto Biológico 69: 261-264.

SUSKI ZW; BADOWSKA T. 1975. Effects of the host plant nutrition on the population of the two spotted spider mite Tetranychus urticae (Koch) (Acarina:Tetranychidae). Ekologia Polska 23: 185-209.

TRANI PE; RAIJ B. Hortaliças. 1996. In: Instituto Agronômico de Campinas. Recomendações de adubação e calagem para o Estado de São Paulo. (Boletim Técnico, 100). 203p.

WERMELINGER B ; OERTLI J J ; BAUMGARTNER J. 1991. Environmental factors affecting the life-tables of Tetranychus urticae (Acari: Tetranychidae). III. Host-plant nutrition. Experimental and Applied Acarology 12: 259-274.

WILSON LJ. 1994. Plant-quality effect on lifehistory parameters of the two spotted spider mite (Acari: Tetranychidae) on cotton. Journal of Economic Entomology 87: 1665-1673. 